\title{
Engineering support of production of high-precision component assemblies
}

\author{
Alexandr Nazaryev ${ }^{1, *}$ and Petr Bochkarev ${ }^{1}$ \\ ${ }^{1}$ Yuri Gagarin State Technical University of Saratov, 410054 Saratov 77 Politechnicheskaya street, Russia
}

\begin{abstract}
In the present paper the discipline of the holistic approach (complex of design procedures) which provide the effectiveness of the realization of the assembly operations is considered. The effective realization of the assembly operations is based on the links between the process design of the manufacturing of the high-precision products and the process design of the assembly production of the high-precision products.
\end{abstract}

Today there is an objective of the engineering output of the high-precision products within a short time and by the short runs before the manufacturing. The required precision is achieved with the traditional methods of manufacturing. They are: the complication of the processing equipment and the applying of the information technologies and measurement technologies [1]. By now, however, the functional precision of the high-precision products (the devices and the machines) has surpassed the precision of the machining equipment and the assembly equipment almost by a decade. This leads to the problem of the achieving of the specified quality and accuracy of the high-precision products during their manufacture [2]. In general, it is solved by the expensive methods, such as the numerous overhauling, reprocessing and amendment of the construction. Moreover, especially at the assembly production stage, the influence of the unknown and outof-control reasons creates the considerable difficulties and causes the unpredictable variation of the specified operational factors [2-4].

The existing methods of the achievement of the assembling precision (fig. 1) are not multipurpose and they depend on the nature of the manufacture and the design features of the products. For instance, the selective assembly method provides the required quality of the assembly of the products from the elements with the precision of the manufacturing which is considerably lower than is needed. It provides a low costs of the manufacture, but it is effective only within the highvolume manufacturing or the mass serial production. Beyond that generally a capability to use the methods such as the selective assembly, the specific adaptation and the adjustment is not forecasted in frames of the assembly of the high-precision products. Appreciably more often the manufacturing manners to achieve the required precision (also called honing processes) are used, what influences negatively on the continuance and the value of the assembly cycle.

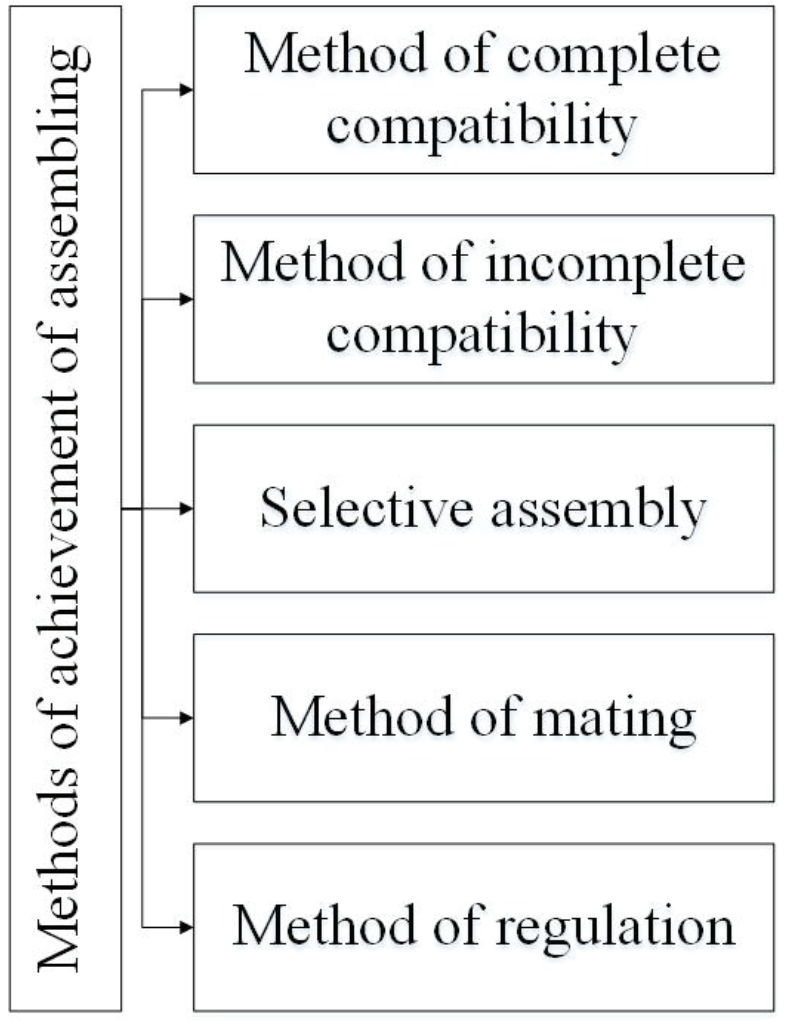

Fig. 1. Methods of the achievement of the assembling

The short terms and the high quality of the process design are the basic requirements of the effective work of the machine-building enterprises. For this very reason it is necessary to conduct researches for the development of the holistic approach to the solving of the machinebuilding issues. Specially the issues, which are applicable to the assembly of the high-precision products [3-4]. Now there are just the segmental solutions for some specific tasks of these issues, such as the upgrading of the quality and the precision of the production, the reduction of the material costs, the adoption of the

\footnotetext{
* Corresponding author: alex121989@mail.ru
} 
resource-saving technologies and so on. But the unifying vision of the system meeting the real requirements does not exist [2].

There is provided an approach (complex of design procedures) established by the linkage between the process design of the manufacturing and the process design of the assembly production meeting the built-in requirements. This linkage is shown at the fig. 2 below. Such approach allows to choose the optimal manufacturing methods of the processing of the units meeting the requirements of the following assembling depending on the real manufacturing situation. In turn, this makes possible to reduce labour inputs, production time and working cost, to improve quality and precision of the high precision products. And to reduce labour inputs and production time during the process design.

The scheme of the complex includes the following procedures:

- Assemblage of the high precision products requirements analysis;

- Analysis of the probable manufacturing methods of the processing of items of the high precision products;

- Choice of the efficient manufacturing methods on the ground of analysis.

The scheme of the complex in general terms is given at the fig. 3 .

The front-end analysis and the design of the efficient manufacturing methods within the system of automated sequencing of manufacturing methods (SASMM) [5-7] include a number of stages.

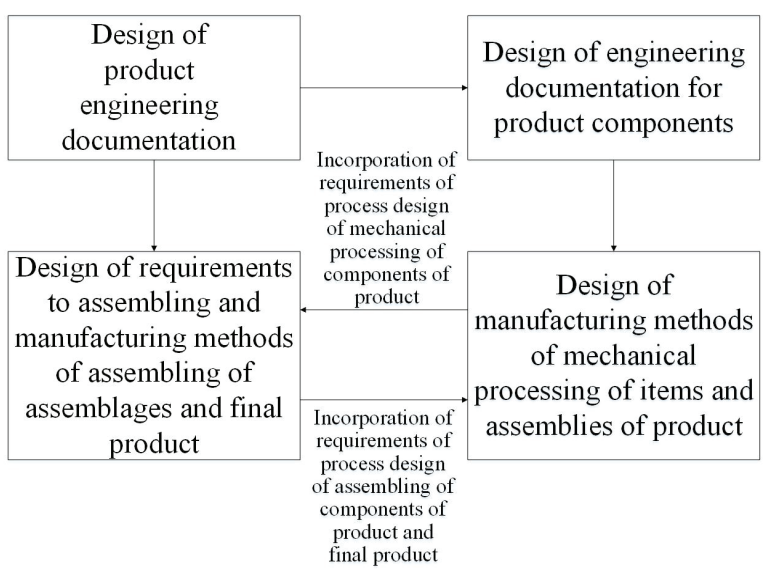

Fig. 2. Linkage between process design of manufacturing and process design of assembly production meeting built-in requirements

The dimensional design analysis of the assembling product and the items, used during the assemblage, and dimensional manufacturing analysis of the variety of the presumable manufacturing methods designed in SASMM are held at the initial stages. The source data for the dimensional design analysis incudes:

- The assembling product engineering documentation;

- The engineering documentation for the items, used during the assemblage.

On the ground of the source data the dimensional design analysis of the assembling product and the items, used during the assemblage is conducted. In the context of this analysis the critical requests of assemblage and items could be established.

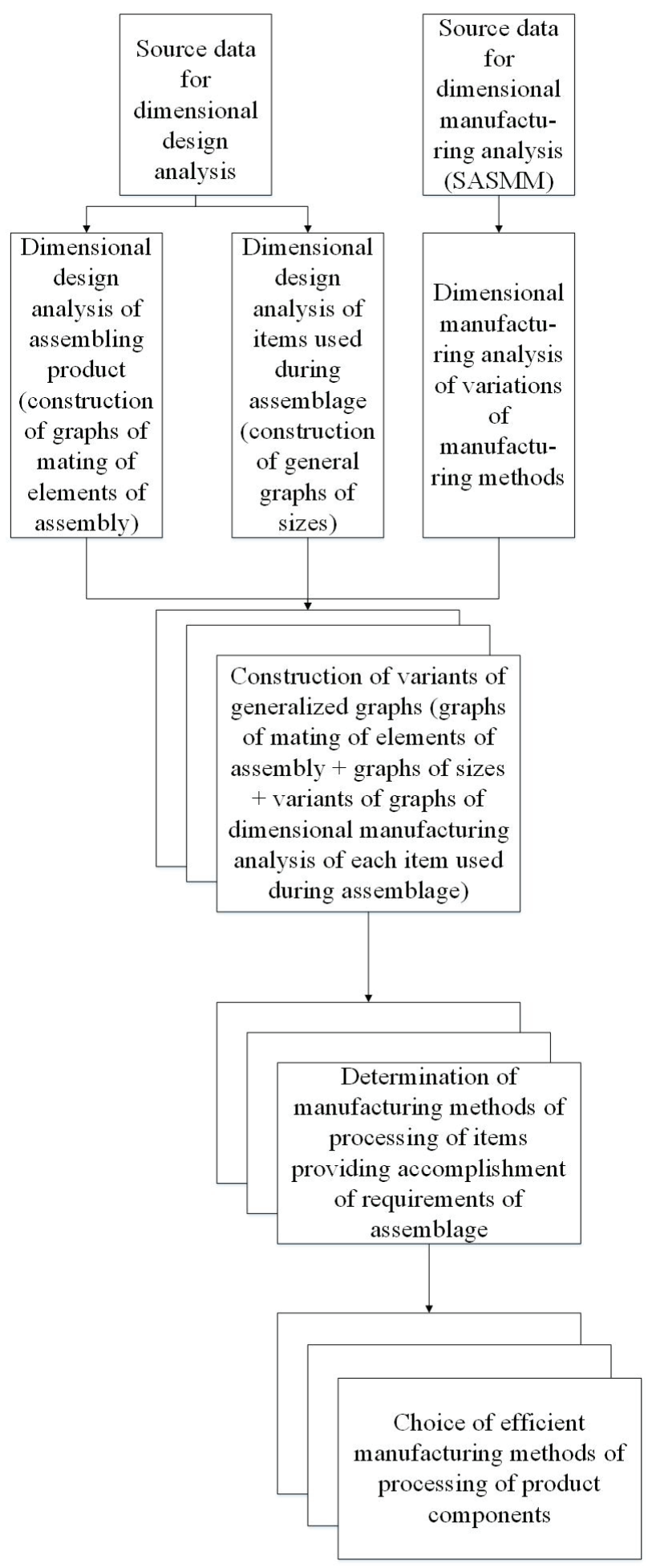

Fig. 3. Scheme of complex of design procedures

A graph with nodes showing elementary surfaces and edges showing their dimensional assignments represents the dimensional assignments of the mechanicalengineering items (assembling products). The graphs of the mating of elements of assembly and the graphs of the sizes are built up in consequence of the dimensional design analysis. The mathematical model of representation and analysis of items and assemblage was 
used for automatisation of the stage. The graphs of the mating of elements of assembly are the source data for this model [8].

Today the design of manufacturing methods is impossible without technologists. This leads to human approach to making decisions at the process design stage following by reduction of effectiveness of the manufacturing systems during the realization of manufacturing methods. Beyond that the design of manufacturing methods with manual methods in the context of multiproduct manufacture renders an analysis of the limited number of variants at the separate designing stages possible. The loss of quality of process engineering solutions and extension of terms are consequence of it. The system of automated sequencing of manufacturing methods is one of the approaches which make it possible to make process design automatic. This system provides the concurrent design of manufacturing methods for the target set of items during the period under consideration with account for an objective manufacturing situation [5-7].

The source data for dimensional manufacturing analysis is set of options of manufacturing methods of production of items used during the assemblage which was received in SASMM.

The dimensional manufacturing analysis consists of construction of graphs of possible manufacturing methods of production of items. The graph of possible manufacturing methods of production of items represents the combining of two trebles, which are called "derived" and "original". The derived treble represents the machining dimensions. The original treble represents the engineering dimensions and dimensions of allowances. This way, graph of the manufacturing method allows to represent the geometric structure of manufacturing method of the processing in coded format. It also could be considered as a mathematical model of the manufacturing method of the processing. Using of such mathematical model allows to choose the optimal manufacturing methods of the processing of the units meeting the requirements of precision of manufacturing and the requirements of assembly of the product in the highest degree.

The item, called "Bush" (fig. 4), and the designing of precision involving (two modifications of the manufacturing methods) the use of the theory of graphs are shown at the fig. 5 ("a" and "b"). Where "A" means the engineering dimensions, " $\mathrm{T}$ " means the machining dimensions, "S" means the ingoing size and "Z" means the allowances for machining.

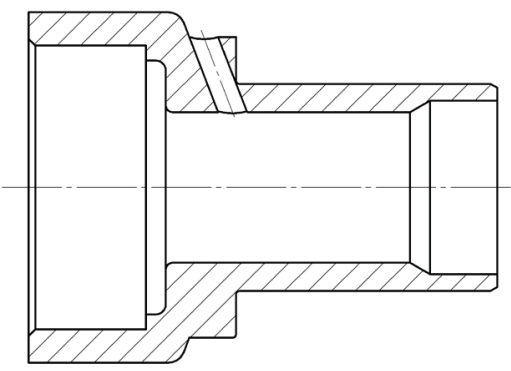

Fig. 4. Item "Bush"
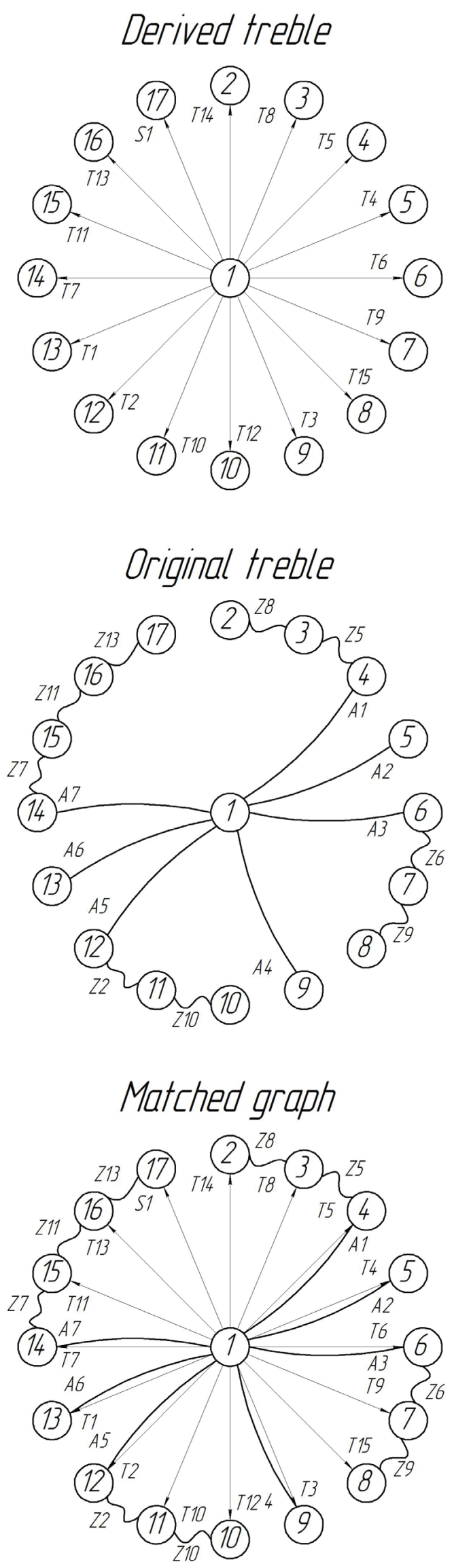

Fig 5.a. Designing of precision for manufacturing method №1 for item "Bush" 

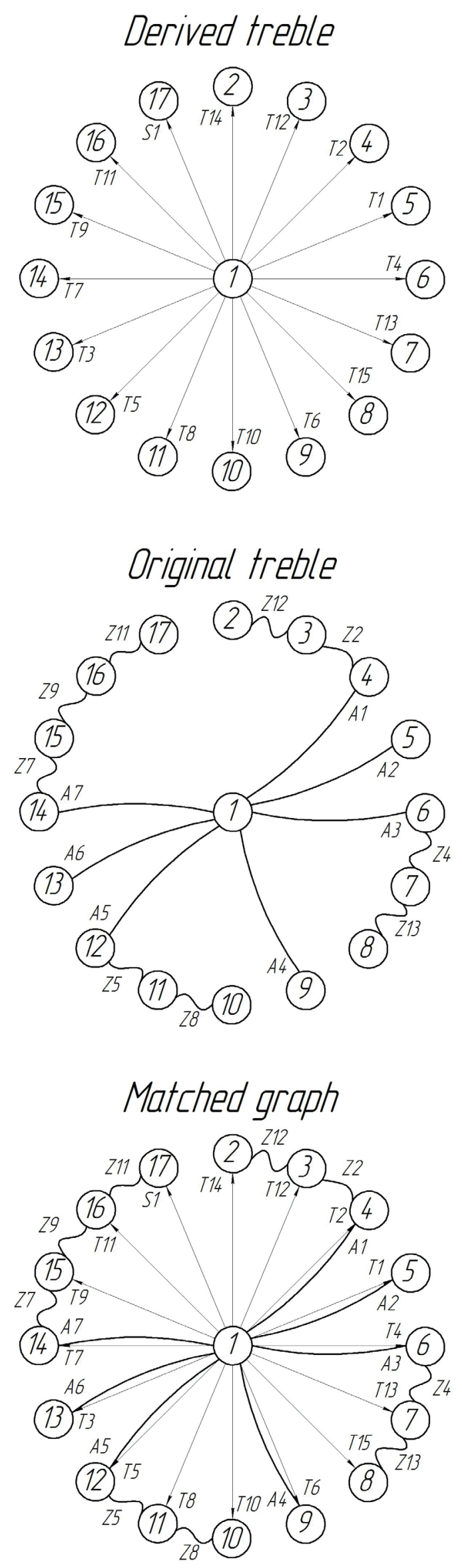

Fig 5.b. Designing of precision for manufacturing method №2 for item "Bush".
The graph of the manufacturing method and the dimension chains are the source data for the approach used for the automatisation of the designing of the manufacturing dimension chains. This approach involves two matrices, one of them is the matrix of nominal dimensions and another is the matrix of allowances. The method in question has some advantages, such as lack of necessity to explore the increasing dimension chain loops and the reducing dimension chain loops and to set up the equations of designing. The other advantage is that it is necessary to construct just the dimension chain and two adjacency matrices (the matrix of allowances and the matrix of nominal dimensions) in order to calculate all sizes and all their allowances. The device also doesn't require any special enumeration for surfaces and allows to automatize the designing of the form deflection circuits and the position deflection circuits. And the other plus point is that the device applies to dimensional analysis of the manufacturing methods of items like "a body of rotation" and more complicated products [9-10].

At the final stage we should choose the set of manufacturing methods of production of items meeting the requirements of assembly. And then it is necessary to define the modification of the efficient manufacturing method with account for an objective manufacturing situation.

\section{The conclusion}

In the present paper the scheme of complex of design procedures providing the effective accomplishment of the assembly operations which is based on the links between the process design of the manufacturing of the high-precision products meeting the built-in requirements and the process design of the assembly production of the high-precision products meeting the built-in requirements is represented. In addition, there are the possible solutions for the complex of design procedures analyzed. The realization of this method in SASMM is relevant because the complex of design procedures allows to consider the objective manufacturing situation and to choose the efficient manufacturing methods of the processing of items with account for requirements of assembly. As a result of that it should be possible to reduce labour inputs, production time and working cost, to improve quality and precision of the high precision products. And also it should be possible to reduce labour inputs and production time during the process design.

\section{References}

1. B.S. Padun, Tool engineering, 8, 12-15 (2014)

2. A.N. Semenov, Tools and technologies, 21 22, 122-124 (2004)

3. A.G. Suslov, A.M. Dal'skij, Scientific fundamentals of technology of mechanical 
engineering (Mashinostroenie Publ., Moscow, 2002)

4. B.M. Bazrov, Fundamentals of technology of mechanical engineering (Mashinostroenie Publ., Moscow, 2005)

5. P.Yu. Bochkaryov, Technology of Mechanical Engineering, 1, 10-14 (2002)

6. S.G. Mitin, P.Yu. Bochkaryov, Science intensive technologies in mechanical engineering, 11 (41), 44-47 (2014)

7. A.V. Nazaryev, P.Yu. Bochkaryov, Science intensive technologies in mechanical engineering, 12, 28-34 (2016)

8. F.V. Grechnikov, S.F. Tlustenko, Vestnik SSAU, 3-4, 38-43 (2011)

9. G. Thimm, G.A. Britton, S.C. Fok, International Journal of Advanced Manufacturing Technology, 261-271 (2004)

10. A.V. Muholzoev, Vestnik YUUrGU. Ser. Mechanical Engineering Industry, 3, 48-55 (2015) 